This item was submitted to Loughborough's Research Repository by the author.

Items in Figshare are protected by copyright, with all rights reserved, unless otherwise indicated.

\title{
Analysis of a free machining $\alpha+\beta$ titanium alloy using conventional and ultrasonically assisted turning
}

PLEASE CITE THE PUBLISHED VERSION

http://dx.doi.org/10.1016/j.jmatprotec.2013.12.002

PUBLISHER

(C) Elsevier

VERSION

AM (Accepted Manuscript)

LICENCE

CC BY-NC-ND 4.0

\section{REPOSITORY RECORD}

Muhammad, Riaz, Mohammad Sajid Hussain, Agostino Maurotto, Carsten Siemers, Anish Roy, and Vadim Silberschmidt. 2013. "Analysis of a Free Machining A+ $\beta$ Titanium Alloy Using Conventional and Ultrasonically Assisted Turning”. Loughborough University. https://hdl.handle.net/2134/14039. 
This item was submitted to Loughborough's Institutional Repository (https://dspace.lboro.ac.uk/) by the author and is made available under the following Creative Commons Licence conditions.

\section{creative
commons}

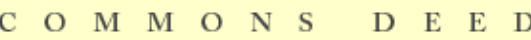

Attribution-NonCommercial-NoDerivs 2.5

You are free:

- to copy, distribute, display, and perform the work

Under the following conditions:

Attribution. You must attribute the work in the manner specified b the author or licensor.

Noncommercial. You may not use this work for commercial purposes.

No Derivative Works. You may not alter, transform, or build upon this work.

- For any reuse or distribution, you must make clear to others the license terms of this work.

- Any of these conditions can be waived if you get permission from the copyright holder.

Your fair use and other rights are in no way affected by the above.

This is a human-readable summary of the Leqal Code (the full license).

\section{Disclaimer 만}

For the full text of this licence, please go to: http://creativecommons.org/licenses/by-nc-nd/2.5/ 
http://dx.doi.org/10.1016/j.jmatprotec.2013.12.002

\title{
Analysis of a free machining $\alpha+\beta$ titanium alloy using conventional and ultrasonically assisted turning
}

\author{
Riaz Muhammad ${ }^{a}$, Mohammad Sajid Hussain ${ }^{b}$, Agostino Maurotto ${ }^{a}$, Carsten \\ Siemers ${ }^{b}$, Anish Roy ${ }^{a^{*}}$, Vadim V. Silberschmidt ${ }^{a}$ \\ ${ }^{a}$ Wolfson School of Mechanical and Manufacturing Engineering, Loughborough University, \\ Loughborough, Leicestershire, LE11 3TU, UK. \\ ${ }^{b}$ Institut fuer Werkstoffe, Technische Universitaet Braunschweig, Langer Kamp 8, D-38106 \\ Braunschweig, Germany \\ *Corresponding author: Tel: +44 1509 227637, Fax: +44 1509 227648, Emai: A.Roy3@lboro.ac.uk
}

\begin{abstract}
Rapid advancements in power generation and aviation industries have witnessed a widespread use of titanium and its alloys in many applications. This is primarily due to their excellent mechanical properties including, amongst other, high strength-to-density ratio, outstanding fatigue properties and corrosion resistance with the ability to withstand moderately high temperatures. However, this combination of properties results in poor machinability of the material, increasing the cost of components machined with conventional cutting techniques. Recently, Ti 6Al 2Sn 4Zr 6Mo, a modern titanium alloy with improved mechanical properties, has been introduced as a possible replacement of Ti 6Al 4V in aerospace industry. However, its poor machinability and formation of long chips in conventional turning are main limitations for its wide-spread application. Therefore, a new alloy based on Ti 6Al 2Sn 4Zr 6Mo, namely Ti 6Al 7Zr 6Mo 0.9La, was developed; it shows
\end{abstract}


http://dx.doi.org/10.1016/j.jmatprotec.2013.12.002

enhanced machinability generating short chips during metal cutting, which prevents entanglement with cutting tools improving productivity. To further enhance the machinability of this material, a novel hybrid machining technique called ultrasonically assisted turning (UAT) was used. Experimental investigations were carried out to study the machinability, chip shapes, cutting forces, temperature in the process zone and surface roughness for conventional and ultrasonically assisted turning of both alloys. UAT shows improved machinability with reduced nominal cutting forces, improved surface roughness of the machined workpiece and generation of shorter chips when compared to conventional machining conditions.

Keywords: Machinability; Free-machining alloy; ultrasonically assisted turning; Titanium alloy; chip formation process

\section{Introduction}

In recent decades, titanium alloys have gained widespread application in the aerospace, power-generation, biomedical and chemical industries, primarily due to a balanced set of desirable properties, such as light weight, high strength, excellent fatigue performance and resistance to an aggressive environment (Peters and Leyens, 2002). However, the main disadvantage of manufacture of titanium components is its poor machinability in conventional machining operations. The tool life is short in turning of titanium alloys due to their high strength, low thermal conductivity and chemical reactivity with tool materials at elevated temperature (Arrazola et al., 2009). In addition, a relatively low Young's modulus of titanium alloys leads to spring-back and chatter leading to poor surface quality of the finished product. 
http://dx.doi.org/10.1016/j.jmatprotec.2013.12.002

Finally, during turning and drilling, long continuous chips are produced, causing their entanglement with the cutting tool and making automated machining almost impossible (Donachie, 2004).

This necessitates the use of low cutting speeds and feeds in conventional machining operations of Ti components, which lead to reduced productivity and increased component costs. The recommended cutting speeds and feed rates for finishing processes are in the range of $0.2 \mathrm{~m} / \mathrm{s}$ to $0.63 \mathrm{~m} / \mathrm{s}$ and $0.15 \mathrm{~mm} / \mathrm{rev}$ to $0.2 \mathrm{~mm} / \mathrm{rev}$, respectively, for titanium alloys (Donachie, 2004). In addition, the time spent to remove chip entanglement from the tool and workpiece increase the production time.

In titanium cutting, chip morphology is one of the most important factors affected by machining parameters (Sima and Özel, 2010). In general, its depends strongly on several parameters, including cutting speed, feed rate, depth of cut, tool geometry and material properties of the tools and titanium workpiece. Kamanduri and Brown (1981) classified the chip morphology into continuous chips, having a constant chips' thickness, segmented chips, showing a saw-tooth like structure and discontinuous chips (fully separated segments) employing the above parameters. Mostly, segmented or discontinuous chip formation was obtained during high-speed cutting of titanium alloys (Shaw and Vyas, 1998). In segmented chips, a narrow zone of high deformation appeared between the segments, the so-called adiabatic shear-band. During the cutting process, deformation localizes in the primary shear zone and temperature increase significantly (Siemers et al., 2012). 
http://dx.doi.org/10.1016/j.jmatprotec.2013.12.002

In the past, the chip-formation process of titanium alloys was intensively studied by means of cutting experiments (Sutter and List, 2013) and simulations (Calamaz et al., 2008). Titanium alloys containing large amounts of $\alpha$-phase at room temperature $(\alpha-$, near- $\alpha$ and $(\alpha+\beta)$-alloys) produced segmented chips for almost all cutting processes and a wide range of cutting conditions, whereas solution-treated metastable $\beta$ - and $\beta$-alloys showed a cutting parameter-dependent change from continuous to segmented chip formation (Siemers et al., 2011b).

There are various ways to improve machinability of titanium alloys, e.g. by external processes such as the application of high-pressure coolant during cutting operations (Ezugwua et al., 2005), by the use of enhanced machining techniques such as ultrasonically assisted turning (UAT) (Maurotto et al., 2013) and other hybrid machining techniques (Rahman Rashid et al., 2012a, b) or by internal processes, e. g. by improving the machinability by alloy modification without significant changes to other material properties (Siemers et al., 2007). The improvements based on the first approach are limited. This can be explained by the high contact pressure between tools and chips in combination with low heat conductivity of titanium that prevents application of coolants directly to the process zone. Additionally, in the recent years, the increased environmental awareness and growing costs have led to a critical re-consideration of conventional cooling lubrication used in machining processes. The costs related to cutting fluids in a manufacturing operation range from $10 \%$ to $20 \%$ of the total costs of the manufactured workpiece, whereas some researchers have claimed that the costs associated with cutting fluids are higher than the cost of cutting tools (Shokrani et al., 2012). Most of these costs are primarily due to environmental requirements: handling of cutting fluids as well as their 
http://dx.doi.org/10.1016/j.jmatprotec.2013.12.002

disposal must obey the strict rules of environmental protections. Therefore, green

manufacturing have become attractive to industries as an alternative to conventional machining with flood supply of cutting fluid (Weinert et al., 2004).

In recent decades, a novel machining technique called ultrasonically assisted turning (UAT), in which low-energy vibro-impacts are superimposed on the movement of cutting tool, preferably in the cutting direction, has shown promise as a viable technique for machining highstrength alloys (Babitsky et al., 2004). Ultrasonically assisted machining was first introduced in the late 1960 s by Skelton (Skelton, 1968). A significant improvement in surface roughness (Maurotto et al., 2012) and substantial reduction in cutting forces was observed in UAT (Muhammad et al., 2013a). Recently, a variant of UAT was proposed by Muhammad et al. (2012b) called hot ultrasonically assisted turning, combining the advantages of hot-machining with those of UAT to yield further benefits in machining intractable alloys such as Ti-15333. There is considerable research work on elliptical ultrasonic machining processes. One of the earliest works by Shamoto and Moriwaki (1994) discussed the advantages of elliptical vibration cutting with regard to reduction of cutting forces and chip thickness in machining of copper. More recently, Zhang et al. (2011) studied the effect of elliptical cutting of hardened steels showing considerable improvements compared to conventional machining. However, major disadvantages of this technique lies in kinematics of the tool motion during a vibratory cycle. The motion of the tool inevitably ends up cutting periodic grooves in the workpiece surface, ultimately affecting the surface quality of the machined workpiece. Reducing the feed rate or the vibration amplitude would improve surface quality but this would ultimately affect machining time. The developed UAT process, discussed in this paper, does not suffer from the 
http://dx.doi.org/10.1016/j.jmatprotec.2013.12.002

said disadvantage of elliptical vibratory machining. Recently, analytical models were developed for ultrasonically assisted oblique turning (Nategh et al., 2012) and 2D vibrational assisted turning (Zhang et al., 2012) to investigate the benefit of this novel machining process.

Alloy modification is another technique in improving machinability, which is more difficult to perform as small changes in the chemical composition can lead to large, unexpected mechanical effects (Hussain et al., 2013). That being said, few attempts have been undertaken to develop free-machining titanium alloys. Kitayama and co-workers, added different rare-earth metals (REM) together with phosphorus $(\mathrm{P})$ or sulphur $(\mathrm{S})$ to achieve distribution of a metal sulphide particles in a titanium alloy (Kitayama et al., 1992). Siemers and co-workers, improved machinability of Ti $6 \mathrm{Al} 4 \mathrm{~V}$ (Ti-64) alloy by the addition of small amounts of cerium (Ce), erbium (Er), lanthanum (La) and neodymium (Nd) (Siemers et al., 2003). It was found that addition of $0.9 \% \mathrm{Ce}$, La or Nd led to formation of short chips due to softening and melting of rare-earthmetal precipitates once the temperature in the primary shear zone increase. This resulted in a decrease in adhesion between segments and chip separation during further progress of the tool. Addition of Er did not improve machinability as its melting point is too high (Siemers et al., 2011a).

Interestingly, it was observed that whenever tin (Sn) was present in the alloys, addition of REM did not improve machinability as $\mathrm{Sn}$ and La form intermetallics like $\mathrm{La}_{5} \mathrm{Sn}_{3}$, which have softening temperature above $1500^{\circ} \mathrm{C}$ (Siemers et al., 2009). In Sn-containing alloys, Sn can be replaced by Zirconium (Zr) ensuring that REM particles are present in the alloys. Similar attempts were made with commercially pure titanium (CP-Titanium Grade 2 and Grade 4), 
http://dx.doi.org/10.1016/j.jmatprotec.2013.12.002

Ti 6Al 2Sn 4Zr 2Mo 0.08Si (Ti-6242S), Ti 15V 3Al 3Cr 3Sn (Ti-15333) and Ti 5Al 5V 5Mo 3Cr 0.5Fe

(Ti5553) (Siemers et al., 2011a).

At present, up to $70 \%$ of titanium alloys produced and used are in the form of Ti-64. Due to its enhanced properties, Ti-6246 alloy will partly replace Ti-64 in aerospace engineering in the near future, especially, in aircraft engine components and airframe structures (Donachie, 2004). However, long chips obtained in turning or drilling of Ti-6246 are the main obstacles for automated machining operations. Therefore, there is an obvious need (1) to suggest new machining techniques for the production chain and (2) to develop new titanium alloys with similar properties but producing discontinuous chips in machining.

In the current work, a new variant of Ti-6246, namely, Ti 6Al 7Zr 6Mo 0.9La (designated as Ti-676-0.9La) was developed and machined with a novel machining technique - UAT - to improve machining operations and demonstrate its viability for automatic manufacture. The obtained results are compared with those for the standard Ti-6246 alloy.

\section{Material and Alloy Production}

The standard Ti-6246 alloy was produced by the GfE-Metalle and Materialien GmbH in Nuremberg, Germany. After 2x vacuum arc remelting (VAR), the alloy was forged from diameter approximately $200 \mathrm{~mm}$ to diameter $75 \mathrm{~mm}$ in the two-phase field followed by air cooling, stressrelief annealing and stripping. To produce comparable results in the machining experiments, this alloy had been remelted once in a plasma-beam cold hearth melter (PB-CHM) followed by casting and stress-relief annealing (as described for the modified alloy in the following paragraph). 
http://dx.doi.org/10.1016/j.jmatprotec.2013.12.002

Implementation of alloy modification was achieved in several stages: (1) $0.9 \%$ of La were added to improve machinability (Siemers et al., 2011b). From earlier studies it was known that La and Sn generated intermetallic phases like $\mathrm{La}_{5} \mathrm{Sn}_{3}$ [6]. Therefore, to avoid their formation, $\mathrm{Sn}$ had to be removed from the modified alloy which acts as a solid-solution hardener (added to the alloys as metallic Sn) without influencing the $\beta$-transus temperature. (2) During alloy modification, Sn could be replaced by $\mathrm{Zr}$ as it does not have a significant influence on the $\beta$ transus temperature and is used for solid-solution hardening as well. To ensure similar solidsolution hardening and $\beta$-transus temperatures in the modified alloy, checked by ThermoCalc ${ }^{\circledR}$ simulations, 3\% Zr were used instead of $2 \%$ Sn meaning that the overall $\mathrm{Zr}$ content in the modified alloy was increased to 7\%. (3) As no multi-phase reactions between Mo and other alloying elements occurred, the Mo content was kept constant. This led to final composition of Ti 6Al 7Zr 6Mo-0.9La containing 6\% Al, 7\% Zr, 6\%Mo, 0.9\%La besides titanium.

The modified alloy was produced by plasma arc melting (PB-CHM) in a laboratory furnace with a capacity of about $350 \mathrm{~g}$ Ti (Rosler et al., 2004). The Ti-676-0.9La alloy was produced from CP-Ti Grade 2 following ASTM B 348, pure Zr (99.9\%), an Al-Mo (52:48) pre alloy to avoid high-density inclusion (HDI) formation during melting, pure Al (99.95\%) and pure La (99.9\%). To ensure sufficient homogeneity of the alloy, it was twice turned by $180^{\circ}$ and remolten after the first melting. The alloy was cast into a water-cooled copper crucible of cylindrical shape (fast cooling). The resulting rods had a diameter of $25 \mathrm{~mm}$ and a length of approximately $50 \mathrm{~mm}$. To remove residual stresses remaining after the casting process and to dissolve possible $\mathrm{Ti}_{3} \mathrm{Al}$ phases, all samples were annealed at $880^{\circ} \mathrm{C}$ for one hour in inert gas atmosphere followed by furnace cooling (solution-treated state). The investigation of 
http://dx.doi.org/10.1016/j.jmatprotec.2013.12.002

mechanical properties of Ti-676-0.9 in comparison to Ti-6246 is underway. Similar levels of hardness indicate that the tensile strength of both alloys should be similar as well. The solutiontreated bars of both alloys were subjected to experiments employing conventional turning (CT) and UAT techniques.

\subsection{Microstructure and Phase Analysis}

Microstructure and phase studies of the two alloys were carried out, and equiaxed grains with a fine lamellar substructures were observed, see Figure 1. Additionally, in the modified alloy, discrete, globular La particles were found, mainly at the grain boundaries (Figure 1a). This is naturally explained by low solvability of La in $\mathrm{Ti}$ in the liquid and solid state. As the melting point of La is lower than that of Ti, a Ti matrix develops, during crystallisation and the remaining melt is enriched in La, leading to trapping of liquid La on the grain boundaries that finally crystallises. The average particle size was about $2 \mu \mathrm{m}$ (Figure 2a). Hard XRD investigations at BW5, HASYLAB, DESY in Germany proved that the La particles were of metallic nature (Figure 2b).
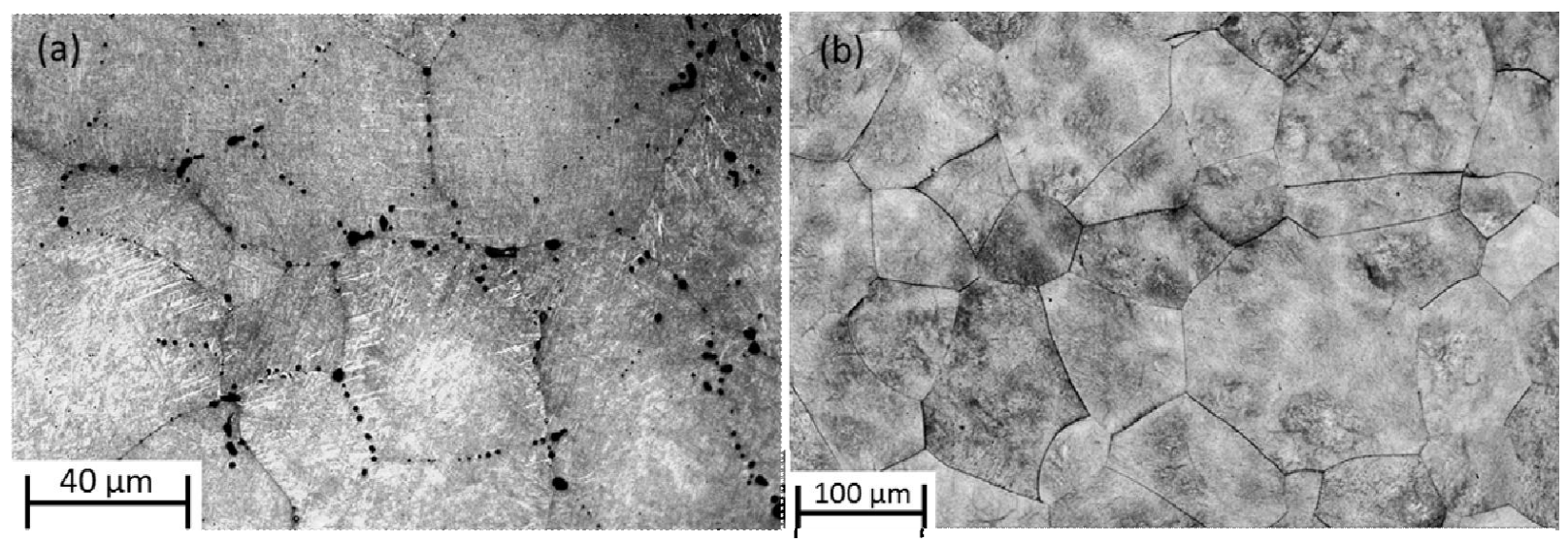

Figure 1: Microstructure of Ti-676-0.9La (a) and Ti-6246 (b) 

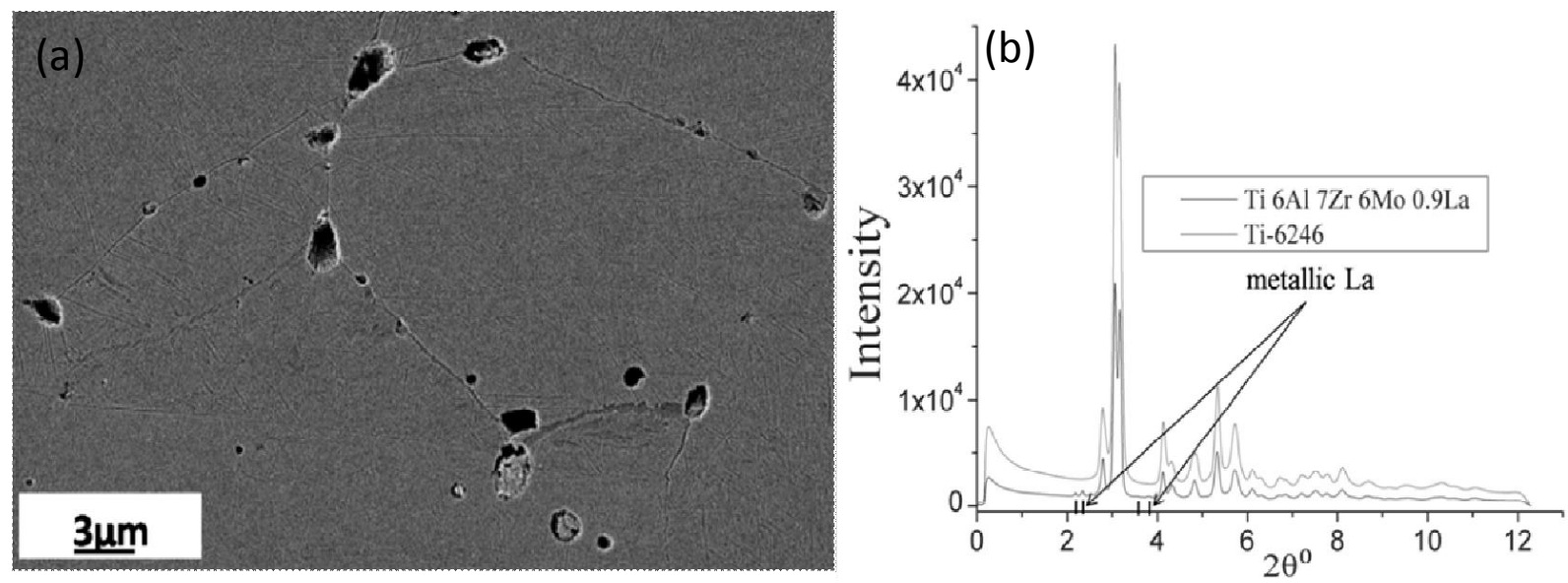

Figure 2: (a) SEM microstructure showing lanthanum particles precipitated at grain boundaries. (b) Hard-XRD patterns for Ti-6246 and Ti-676-0.9La indicate the metallic nature of the particles (Hussain et al., 2013).

The average grain sizes of Ti-676-0.9La was $43 \mu \mathrm{m} \pm 12 \mu \mathrm{m}$ and $147 \mu \mathrm{m} \pm 13 \mu \mathrm{m}$ for Ti6246 alloy, see Figure 1. This indicates that the La particles either act as additional nuclei during crystallisation and/or hinder grain growth during cooling of the modified alloy in the solid state.

Based on these observations, heat treatment of both alloys was carried out at different temperatures - slightly below and above their $\beta$-transus temperature to study their grain-size stability. It was found that no grain growth occurred in Ti-676-0.9La at temperatures below $\beta$ transus whereas severe grain growth was observed in the standard Ti-6246 alloy in all heat treatments (Figure 3). This confirms the grain size stabilization effect of lanthanum in $(\alpha+\beta)$ titanium alloys (Hussain et al., 2013). 
http://dx.doi.org/10.1016/j.jmatprotec.2013.12.002

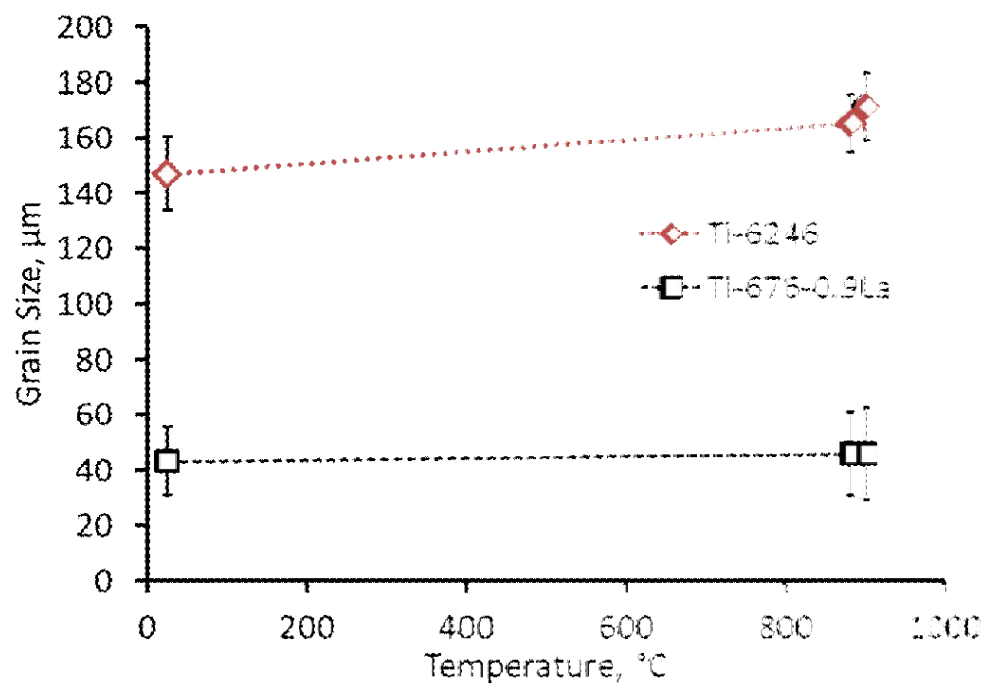

Figure 3: Grain size for various temperatures in both alloys (Hussain et al., 2013)

\section{Cutting Tool and Cutting Conditions}

In cutting tests of the studied alloys, cemented-carbide cutting inserts with a ceramic coating of titanium-aluminium-nitride on top of a layer of titanium-nitride (CP500) were used, as suggested for cutting depths ranging from $0.2 \mathrm{~mm}$ to $0.300 \mathrm{~mm}$ with a feed rate of 0.05 $\mathrm{mm} / \mathrm{rev}$ to $0.25 \mathrm{~mm} / \mathrm{rev}$ and cutting speeds of about $45 \mathrm{~m} / \mathrm{min}$ (as specified by the manufacturer). The tool had a nose radius of $0.8 \mathrm{~mm}$, a rake angle of approximately $14^{\circ}$ and clearance angle of $0^{\circ}$.

The cutting conditions used in the experiments are listed in Table 1. Round bars of both alloys were initially turned on a lathe with coolant to remove the residual effect of manufacturing and environmental conditions on the studied alloys. The ingot bars were mounted on a Harrison lathe and the eccentricity was adjusted with the help of a mechanical dial gauge. Experiments were carried out for CT and UAT for various cutting speeds at a depth of 
http://dx.doi.org/10.1016/j.jmatprotec.2013.12.002

cut of $0.2 \mathrm{~mm}$ using a relatively low feed rate $(t)$ of $0.1 \mathrm{~mm} / \mathrm{rev}$ recommended for finishing operations of Ti-alloys (Donachie, 2004).

Table 1. Cutting conditions used in experiments

\begin{tabular}{ll}
\hline Parameters & Magnitude \\
\hline Cutting speed, $V(\mathrm{~m} / \mathrm{min})$ & $10 ; 30 ; 60$ \\
Depth of cut, $a_{p}(\mathrm{~mm})$ & 0.2 \\
Feed rate, $f_{r}(\mathrm{~mm} / \mathrm{rev})$ & 0.1 \\
Vibration frequency in UAT, $f(\mathrm{kHz})$ & 20 \\
Vibration amplitude in UAT, $a(\mu \mathrm{m})$ & 10 \\
\hline
\end{tabular}

\section{Experimental Setup}

A customized Harrison 300 lathe was used to carry out CT and UAT of both alloys as shown in

Figure 4. The lathe was modified with a customized ultrasonic transducer fixed to a cross waveguide to superimpose ultrasonic vibration on the movement of a cutting tool, in UAT (Muhammad et al., 2012a). A schematic diagram of the experimental setup is shown in Figure 4a. A digital signal generator was used to generate a low-current driving signal of $10 \mathrm{~V}$ (peak-topeak), which was amplified for driving the transducer. The signal was then supplied to the piezoelectric rings converting electrical energy into mechanical vibration with a maximum efficiency of 0.95. A non-contact measurement technique (Poly-tech laser vibro-meter) was used to monitor vibration parameters in the turning tests. Cutting tests were performed for both machining techniques, and each experiment was repeated at least five times to get good statistical data. The cutting forces were measured with a three-component Kistler 
http://dx.doi.org/10.1016/j.jmatprotec.2013.12.002

dynamometer (KIAG-SWISS Type-9257A), fixed to the ultrasonic head assembly to record the cutting forces (see Figure $4 \mathrm{~b}$ ). The dynamometer has a sensitivity of $\pm 0.1 \mathrm{~N}$ and can measure the two components of force $F_{x}$ and $F_{y}$, in turning. The output signals from the dynamometer were supplied to a Kistler 5001 amplifier to convert them to high-amplitude signals. The amplified signals were processed in an advanced four-channel digital oscilloscope (analogue-todigital converter), Picoscope 4424, and finally recorded in a computer (Figure 4a). The dataacquisition system yields an average of the force over a large number of cycles of ultrasonic vibration as recorded from the dynamometer. For cutting force analysis, each experimental test lasted for approximately $70 \mathrm{~s}$. Within the first 10 to $15 \mathrm{~s}$, the depth of cut was set to a desired magnitude followed by CT for 25-30 s as shown in the force history diagram (Figure 5). During the test, ultrasonic vibration was switched on after $40 \mathrm{~s}$ and lasted for approximately $20 \mathrm{~s}$ before being switched off to recover CT the regime for the rest of $10 \mathrm{~s}$. 


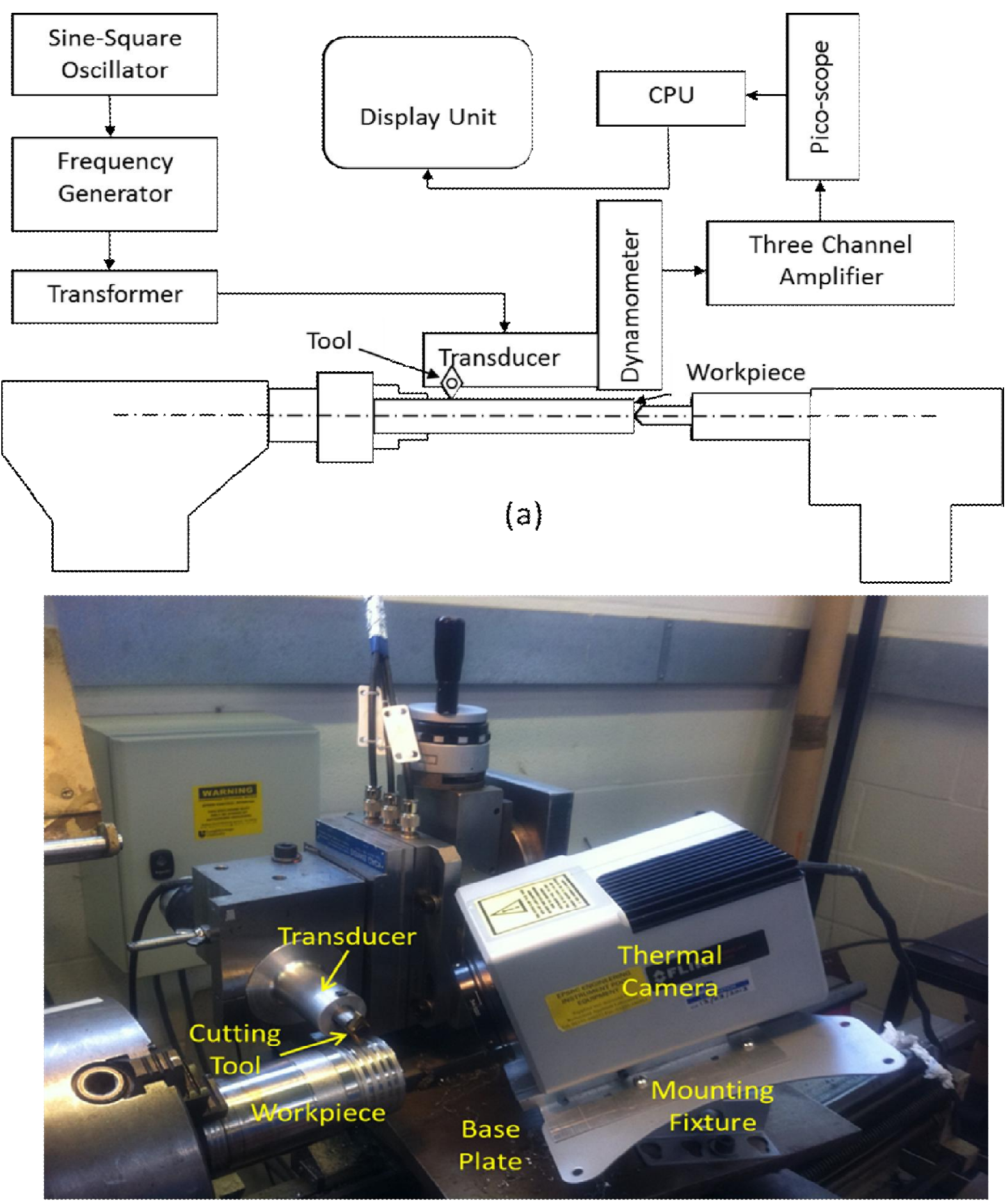

(b)

Figure 4: Schematic diagram of the experimental setup (a); experimental setup for CT and UAT (b) 


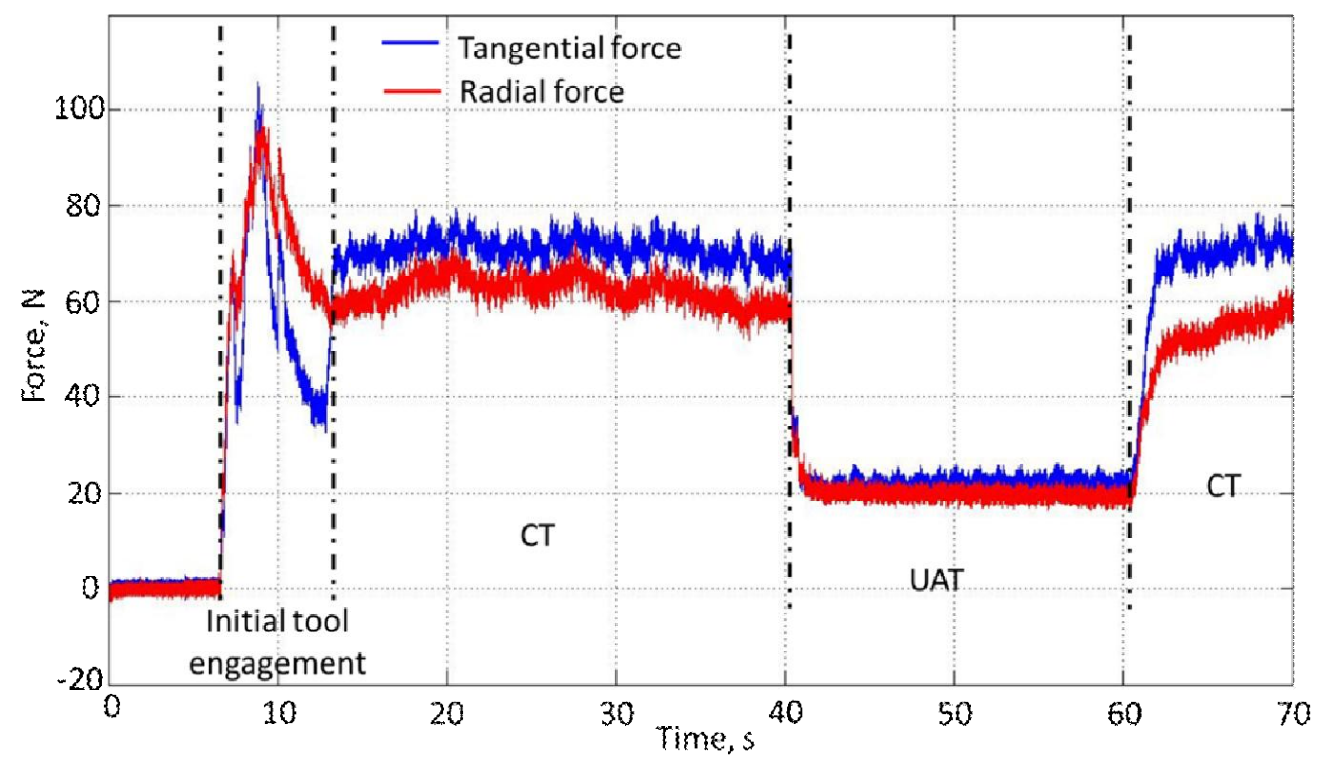

Figure 5: Force history in CT and UAT for Ti-676-0.9La at $a_{p}=0.2 \mathrm{~mm}$ and $V=10 \mathrm{~m} / \mathrm{min}$

Additionally, the amount of heat generated in CT and UAT in the process zone in turning of both alloys, which has a significant effect on the sub-surface deformation, metallurgical structure and tool life, needed to be investigated. Therefore, in this study, the FLIR ThermaCAM ${ }^{\mathrm{TM}}$ SC3000 camera was used to carry out thermal analysis. The system was mounted on a special fixture, and data obtained for CT and UAT were recorded (Figure 6), using a continuous mode operation. The data were later analysed for various cutting conditions, and only average temperature values were used in the analysis. 

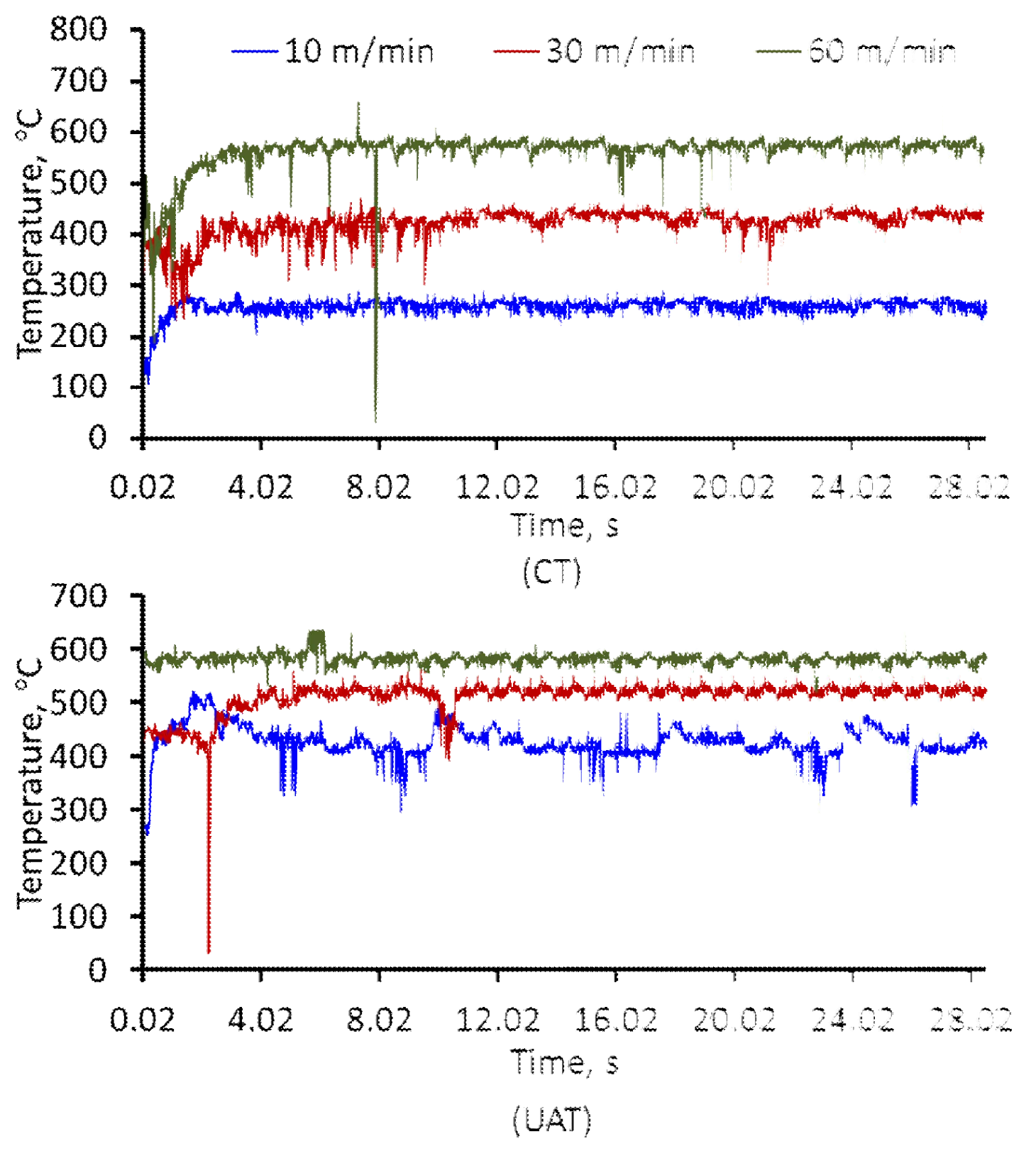

Figure 6: Temperature history for CT and UAT of Ti-6246 at $a_{p}=0.2 \mathrm{~mm}$ for various cutting speeds. 
http://dx.doi.org/10.1016/j.jmatprotec.2013.12.002

Post-turning, analysis was carried out using Zygo interferometry (NewViewTM 5000 series) to characterize the machined surface for CT and UAT for both alloys. In addition to that, chip samples were collected and analysed using Scanning Electronic Microscopy (SEM).

\section{Results and Discussion}

\subsection{Chip Morphology}

In the turning experiments at various cutting conditions, chips were collected and analysed with respect to their morphology and geometry. In machining of the standard Ti-6246 alloy, long continuous chips were developed in CT and UAT at various cutting conditions. Chips of the modified alloy (Ti-676-0.9La), in contrast, were discontinuous in both CT and UAT as shown in Figure 7. The difference in the length of the chips is clearly visible and was apparent for various cutting conditions, even at low cutting speeds (e.g. $10 \mathrm{~m} / \mathrm{min}$ ). 

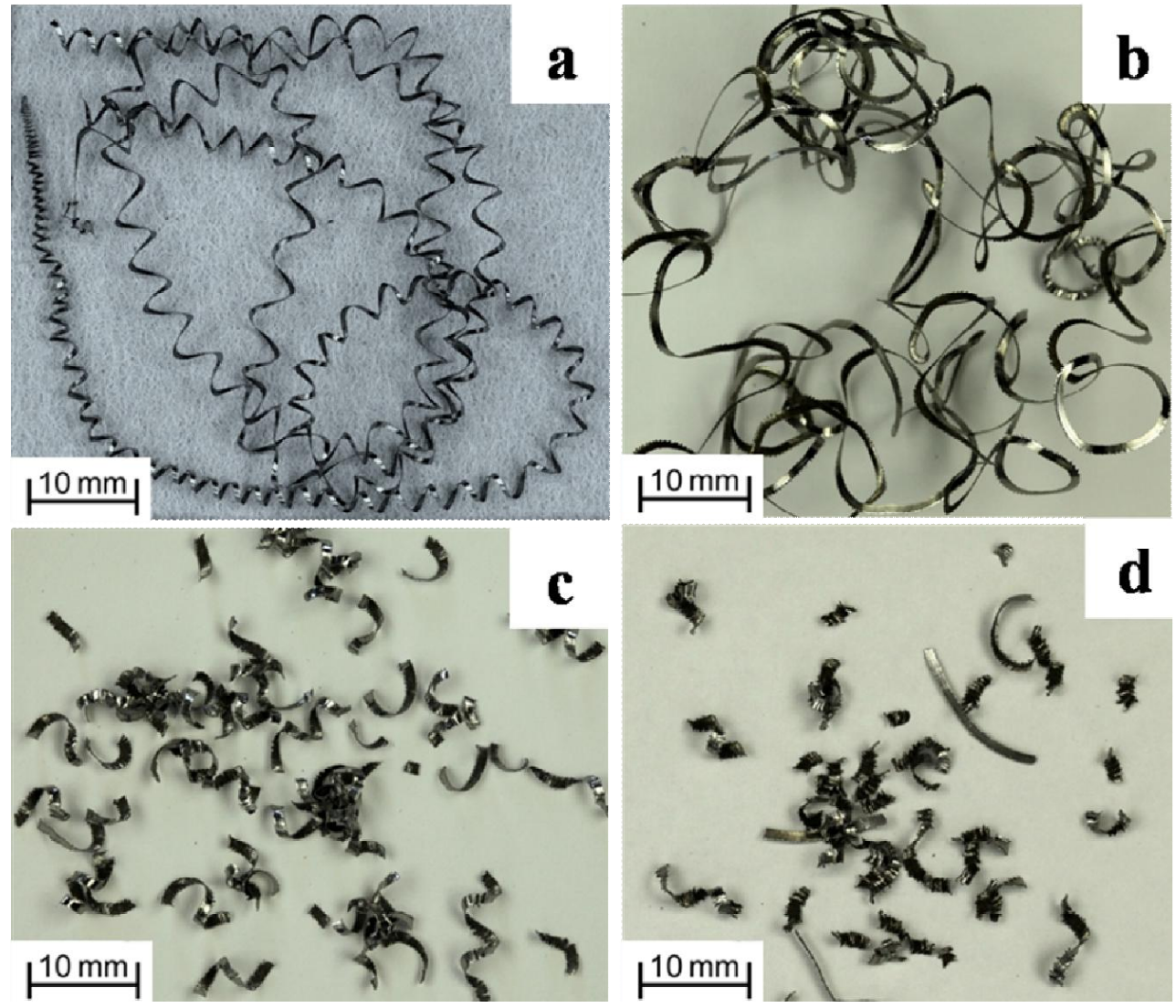

Figure 7: Chip formed in turning processes: Ti-6246 in CT (a); Ti-6246 in UAT (b);

Ti-676-0.9 in CT (c); Ti-676-0.9 in UAT (d). The difference in the chips' length is clearly visible.

The formation of short chips in the modified alloy in CT and UAT can be explained as

follows: during chip segmentation, the high temperature in the shear bands softens drastically

or even melts the metallic lanthanum particles that are present in the zone of localized

deformation. This results in diminished adhesion between the segments, which fall apart during further progress of the tool. In UAT of the modified alloy, vibro-impact events at the toolworkpiece-interface pulverize the chip, and shorter and less curved chips are obtained when compared to CT. Since in Ti-6246 no La particles are present, long continuous chips are formed both in CT and UAT. SEM analyses of the chips show that chip separation occurs in almost each 
segment in case of the Ti-676-0.9La alloy, whereas in Ti-6246 good cohesion was observed in the segmented chip (Figure 8).

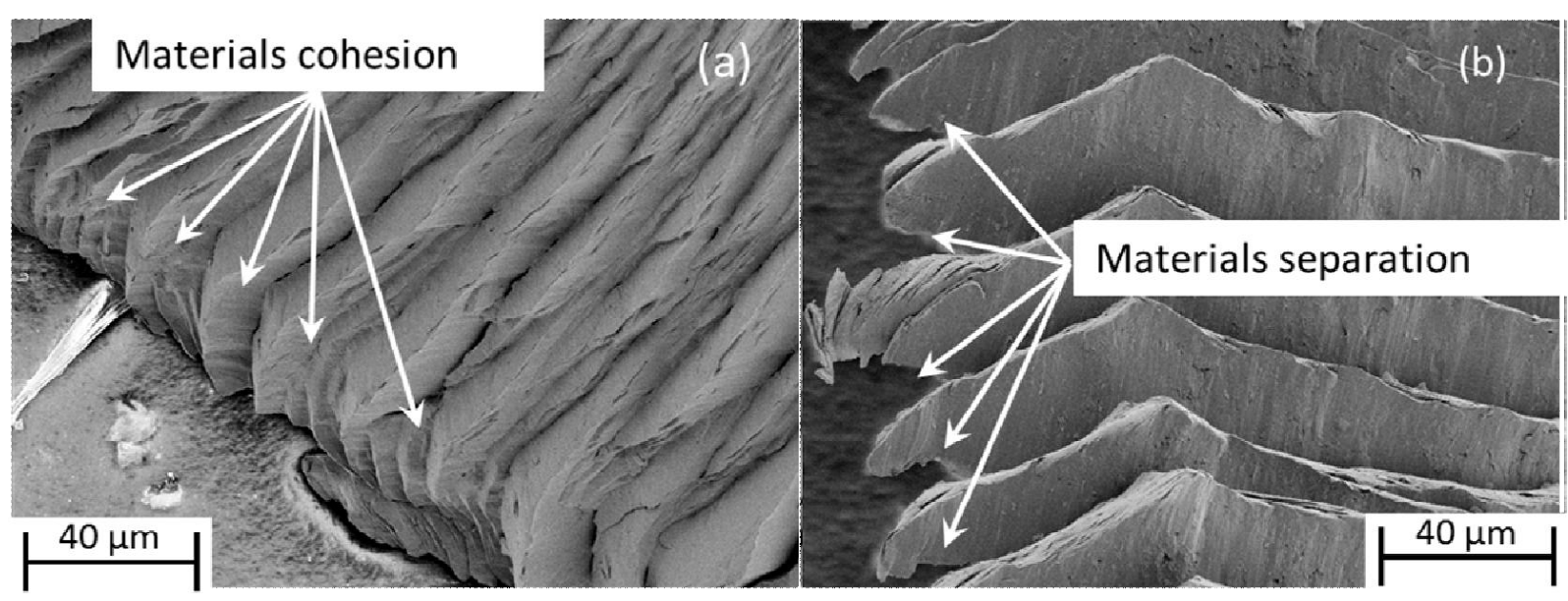

Figure 8: Chip morphology for UAT of Ti-6246 (a) and Ti-676-0.9La (b) at at $a_{p}=0.2 \mathrm{~mm}$ and $V=$ $10 \mathrm{~m} / \mathrm{min}$

\subsection{Effect of Cutting Parameters on Chip Geometry}

In order to get a better understanding of the chip formation process, chip compression ratio $(\lambda)$ was analysed for both alloys. Cross sections of chips of the two studied titanium alloys were analysed with optical microscopy for various cutting parameters (Figure 9). To do so, quantitative image analyses were performed (with ImagJ software), and the chip compression ratio was calculated using the following equation.

$$
\lambda=\frac{h_{\max }+h_{\min }}{2 d_{c}},
$$

where $d_{c}$ is the chip thickness and $h_{\max }$ and $h_{\min }$ are the maximum and minimum heights of the segment, respectively. 


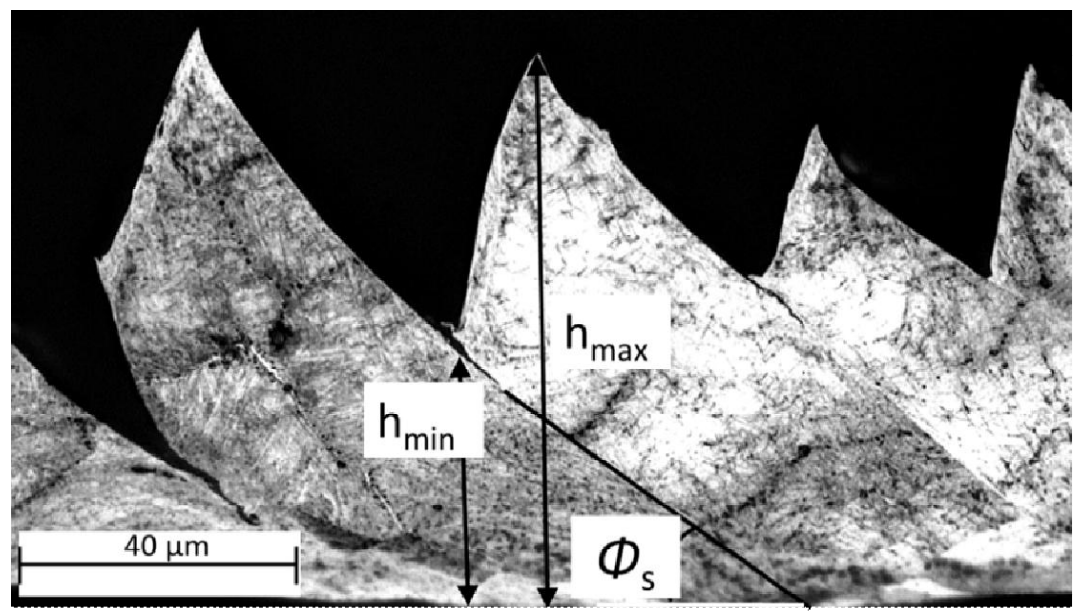

Figure 9: Definition of geometrical parameters used for comparison of different chips

The chip compression ratio increased with an increase in cutting speed for both alloys. However, a higher chip compression ratio was observed in UAT when compared to CT in both alloys as shown in Figure 10. The main reason for the high compression ratio in UAT is the additional energy superimposed on the tool in form of vibration, resulting in a relatively higher tool velocity compared to CT Furthermore, a higher chip compression ratio was observed in Ti676-0.9La when compared to Ti-6246 in both CT and UAT; this is due to the presence of lanthanum particles at the grain boundaries and in the shear bands changing kinematics of the chip formation processes and separation. 


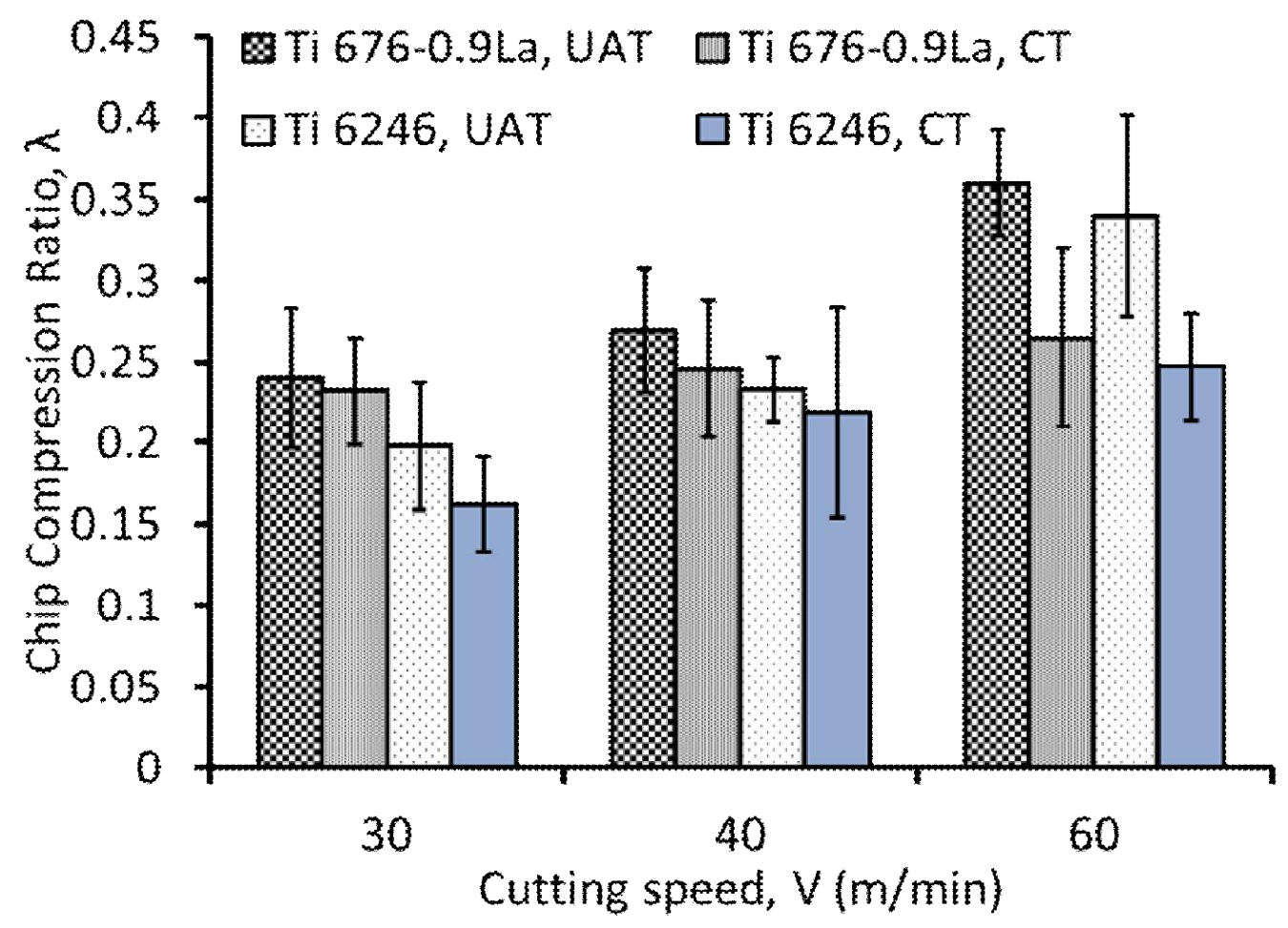

Figure 10: Chip compression ratio for both alloys machined with CT and UAT at $a_{p}=0.2 \mathrm{~mm}$ for various cutting speeds.

\subsection{Cutting Forces}

Application of ultrasonic vibration to the cutting tool brought a noticeable reduction in the cutting forces for both alloys (Figure 11 and Figure 12). In this work, the average cutting forces were used in the analysis. A significant reduction (74\%) in tangential component of the cutting forces was observed for application of vibration at the cutting speed of $10 \mathrm{~m} / \mathrm{min}$ in both alloys. Similarly, UAT also considerably reduced the radial component of the cutting force. An average reduction of $59 \%$ and $74 \%$ in Ti-6246 and Ti-676-0.9La were measured at $10 \mathrm{~m} / \mathrm{min}$, respectively. The level of both cutting forces (the tangential and the radial) was slightly reduced with an increase in the cutting speed in CT in Ti-6246 (Figure 11) whereas in Ti-676-0.9La the 
http://dx.doi.org/10.1016/j.jmatprotec.2013.12.002

cutting force decreased somewhat at $30 \mathrm{~m} / \mathrm{min}$ but then increased marginally at $60 \mathrm{~m} / \mathrm{min}$ (when compared to cutting forces at $10 \mathrm{~m} / \mathrm{min}$ ).

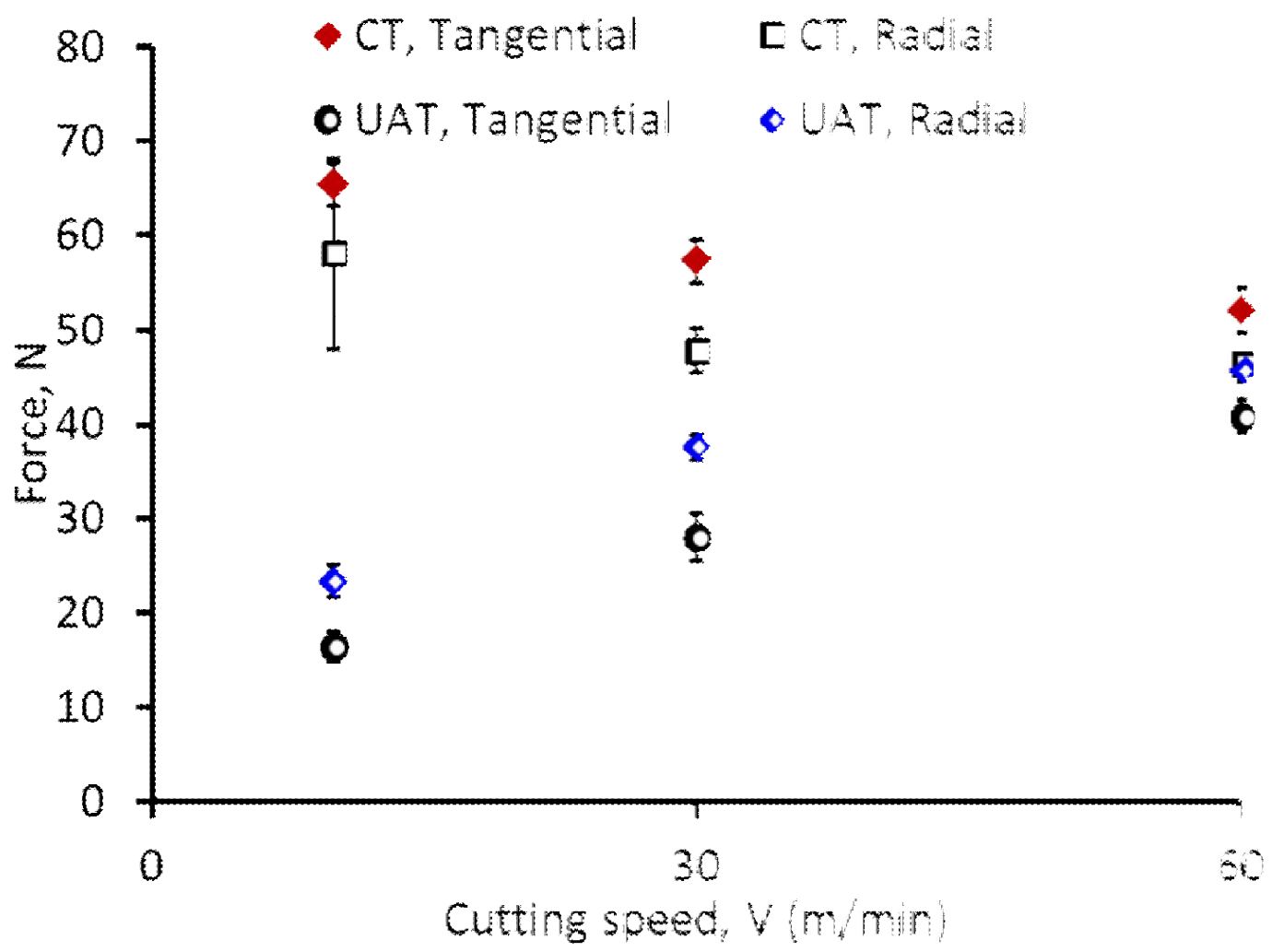

Figure 11: Cutting forces in CT and UAT of Ti-6246 at $a_{p}=0.2 \mathrm{~mm}$ for various cutting speeds. 


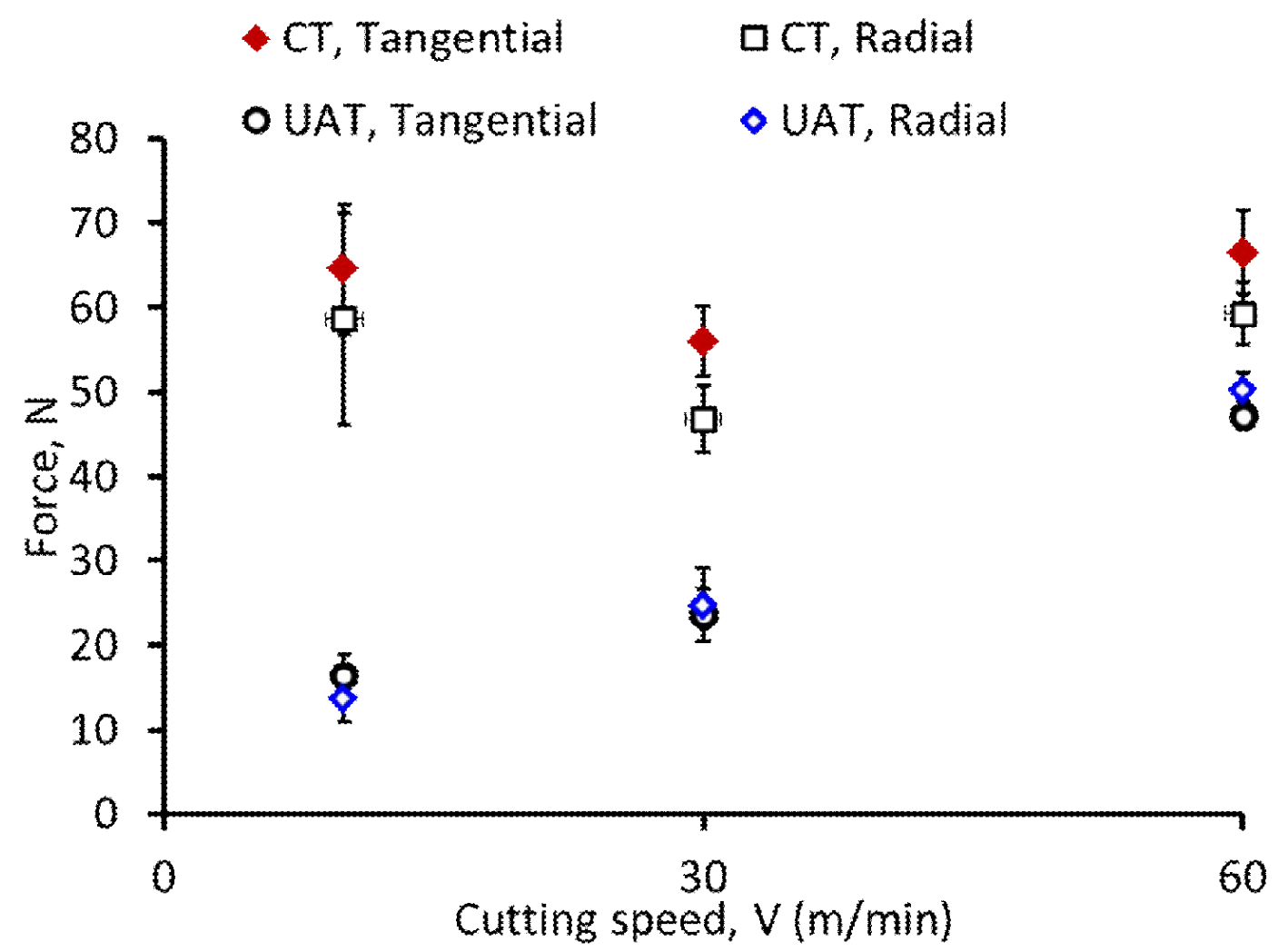

Figure 12: Cutting forces in CT and UAT of Ti-676-0.9La at $a_{p}=0.2 \mathrm{~mm}$ for various cutting speeds.

UAT is characterised by the critical cutting speed, which is a function of applied vibration amplitude and frequency:

$$
V_{c}=2 \pi a f
$$

where $f$ is the frequency and $a$ is an amplitude of vibration superimposed on the cutting tool. In the current experimental setup, the critical velocity is calculated to be $75.32 \mathrm{~m} / \mathrm{min}$. In UAT, with an increase in the cutting speed, separation between the tool and workpiece is reduced, causing a decline in force reduction. Therefore, it is no surprise that the cutting forces increased with the increased cutting speed and, ultimately, the reduction in cutting forces vanished near 
http://dx.doi.org/10.1016/j.jmatprotec.2013.12.002

the critical velocity limit (Figure 13). At $10 \mathrm{~m} / \mathrm{min}$ to $30 \mathrm{~m} / \mathrm{min}$, the reduction in the tangential component of forces was $51 \%$ and $57 \%$ for Ti-6246 and Ti-676-0.9La, respectively, when compared to CT. Similarly, a reduction of $21 \%$ and $47 \%$ in the radial cutting forces was observed for the same cutting speed. At a higher cutting speed of $60 \mathrm{~m} / \mathrm{min}$, a considerable reduction of $21 \%$ and $28 \%$, respectively, in the tangential component of forces was measured for Ti-6246 and Ti-676-0.9La. However, the reduction in the radial component of force in Ti-6246 was significantly lower compared to that for Ti-676-0.9La (15\%). As cutting velocity is still lower than the critical velocity of the system, therefore, caused a reduction in cutting forces.

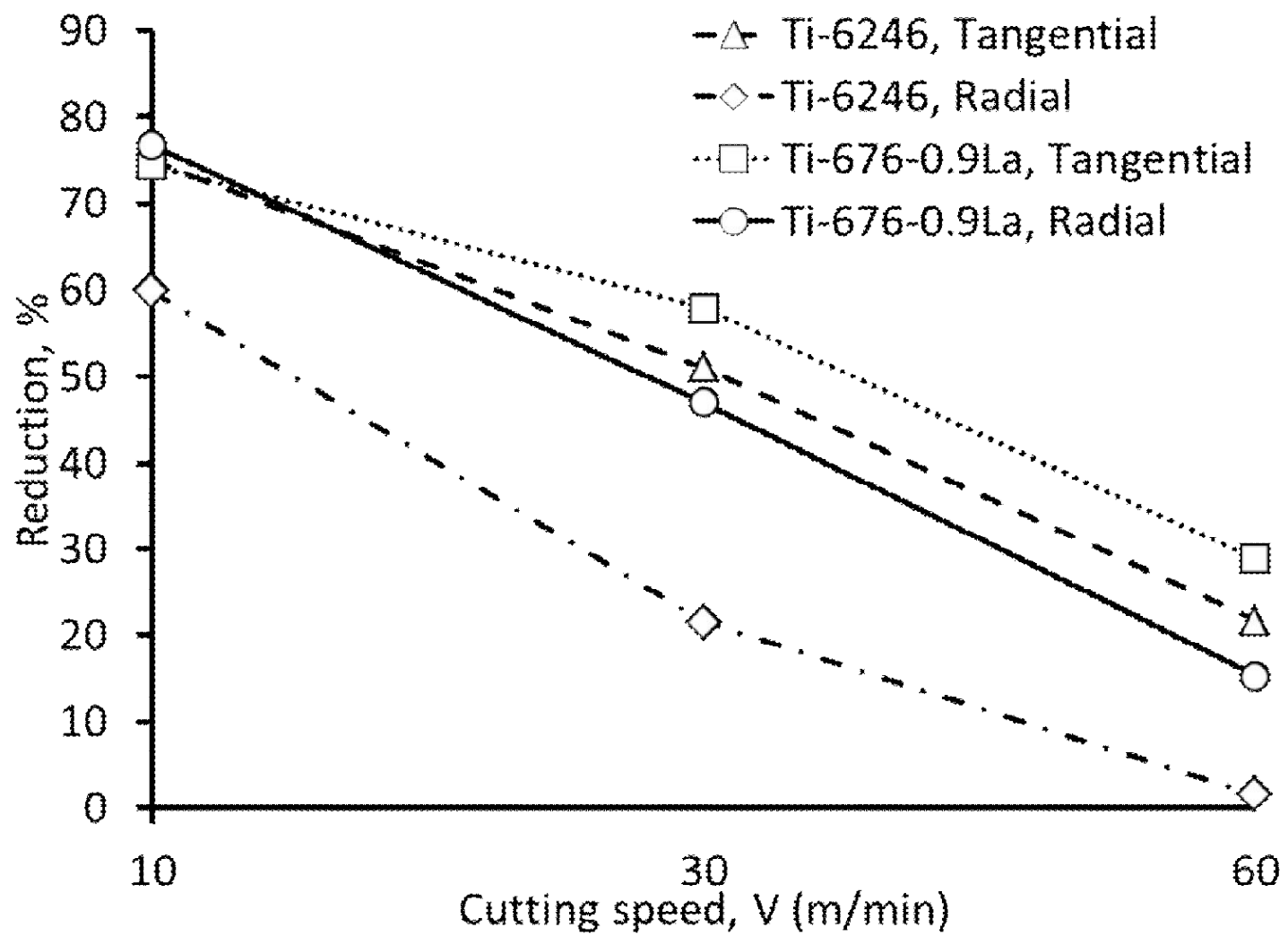

Figure 13: Reduction in cutting forces in UAT at $a_{p}=0.2 \mathrm{~mm}$ for various cutting speeds.

\subsection{Temperature in Process Zone}


http://dx.doi.org/10.1016/j.jmatprotec.2013.12.002

Temperature in the process zone in CT and UAT was also investigated experimentally, as shown in Figure 14 for both alloys. Obviously, the obtained results are for the visible area due to the obstruction created by the chip while recording the temperature at the process zone. It was difficult to align the camera at a preferable orientation due to the constraints created by the lathe machine used. Still our results show that the chip temperature was higher in UAT when compared to $\mathrm{CT}$, indicating that the process-zone temperature was higher in UAT.

There is some debate in the literature concerning the nature of friction in ultrasonic/vibratory machining processes. However, it is well known that the primary cause of heat generated in metal cutting is due to the plastic work in the primary and secondary shear zones of the chip with minimal contribution from the friction between tool and the workpiece, which is estimated to be below $10 \%$ (Komanduri and Hou, 2002). Our experimental studies indicate that ultrasonic machining inevitably leads to an increase in the process-zone temperature when compared to that of conventional processes. Thus, the effect of friction is expected to be small in contributing to increase in temperature in UAT. A possible reason for this is due to the amount of additional energy applied to the tool in the form of vibrations (Muhammad et al., 2012a).

A noticeable increase in nominal temperature of the cutting region was observed with an increase in the cutting speed in both CT and UAT for both alloys as expected (Figure 15). However, the amount of heat generated in Ti-676-0.9La was higher in CT and UAT when compared to that in Ti-6246. This higher temperature further facilitated pulverization of chips in UAT, and discontinuous chips were obtained. Temperatures of the process zone in CT and UAT in Ti-676-0.9La were approximately $100^{\circ} \mathrm{C}$ to $150^{\circ} \mathrm{C}$ higher when compared to those for Ti-6246. 
The possible reason is the amount of additional energy applied to the tool in the form of vibrations (Muhammad et al., 2012c).
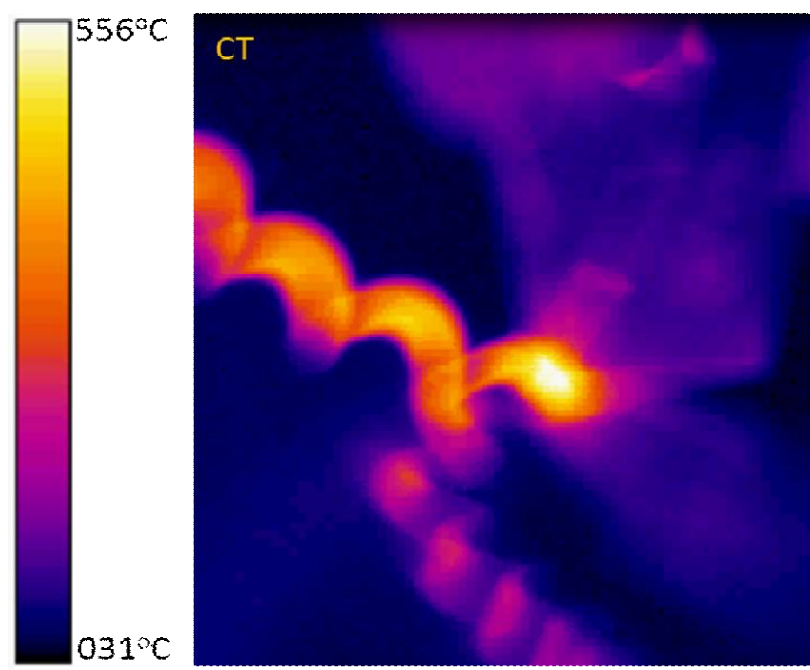

(a)

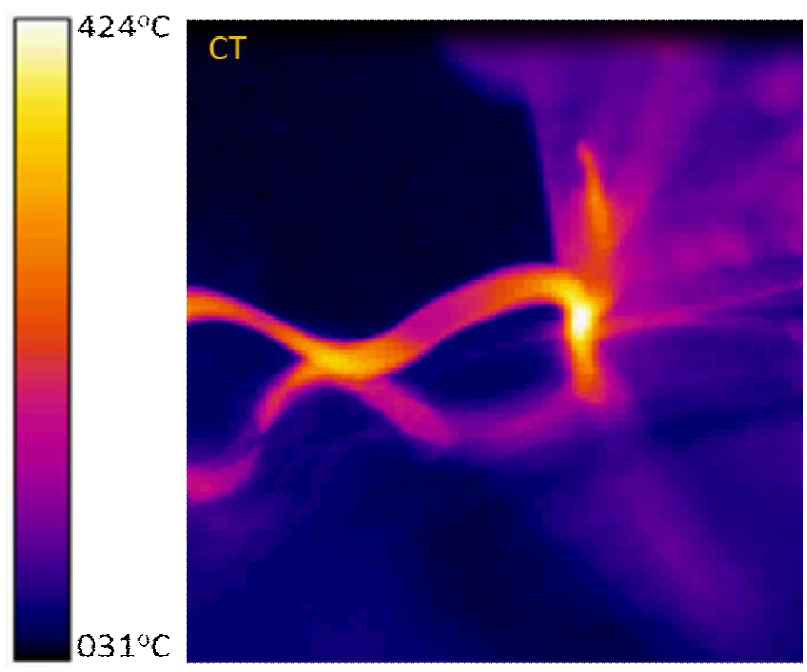

(c)
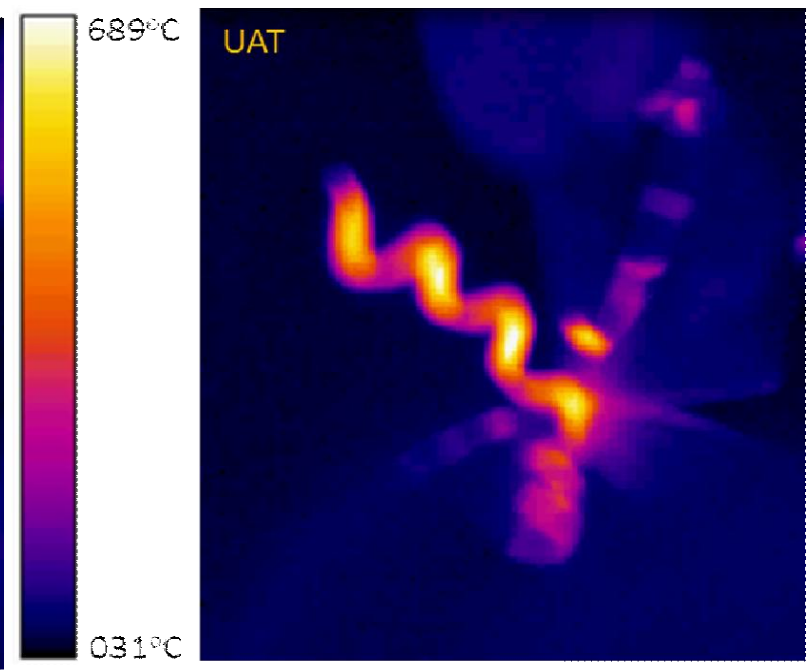

(b)

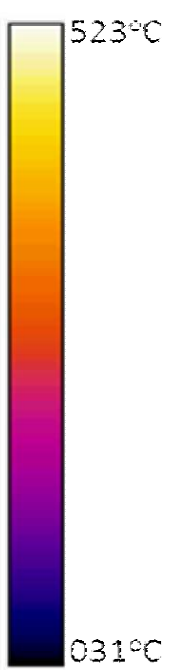

03100

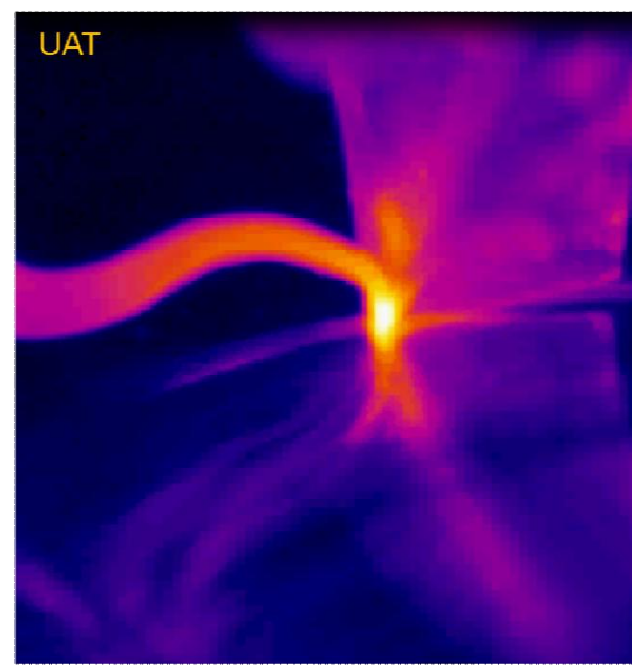

(d)

Figure 14: Temperature in process zone in CT and UAT: Ti-676-0.9La (a, b); Ti-6246 (c, d) at $a_{p}=$ $0.2 \mathrm{~mm}$ and $V=30 \mathrm{~m} / \mathrm{min}$ 


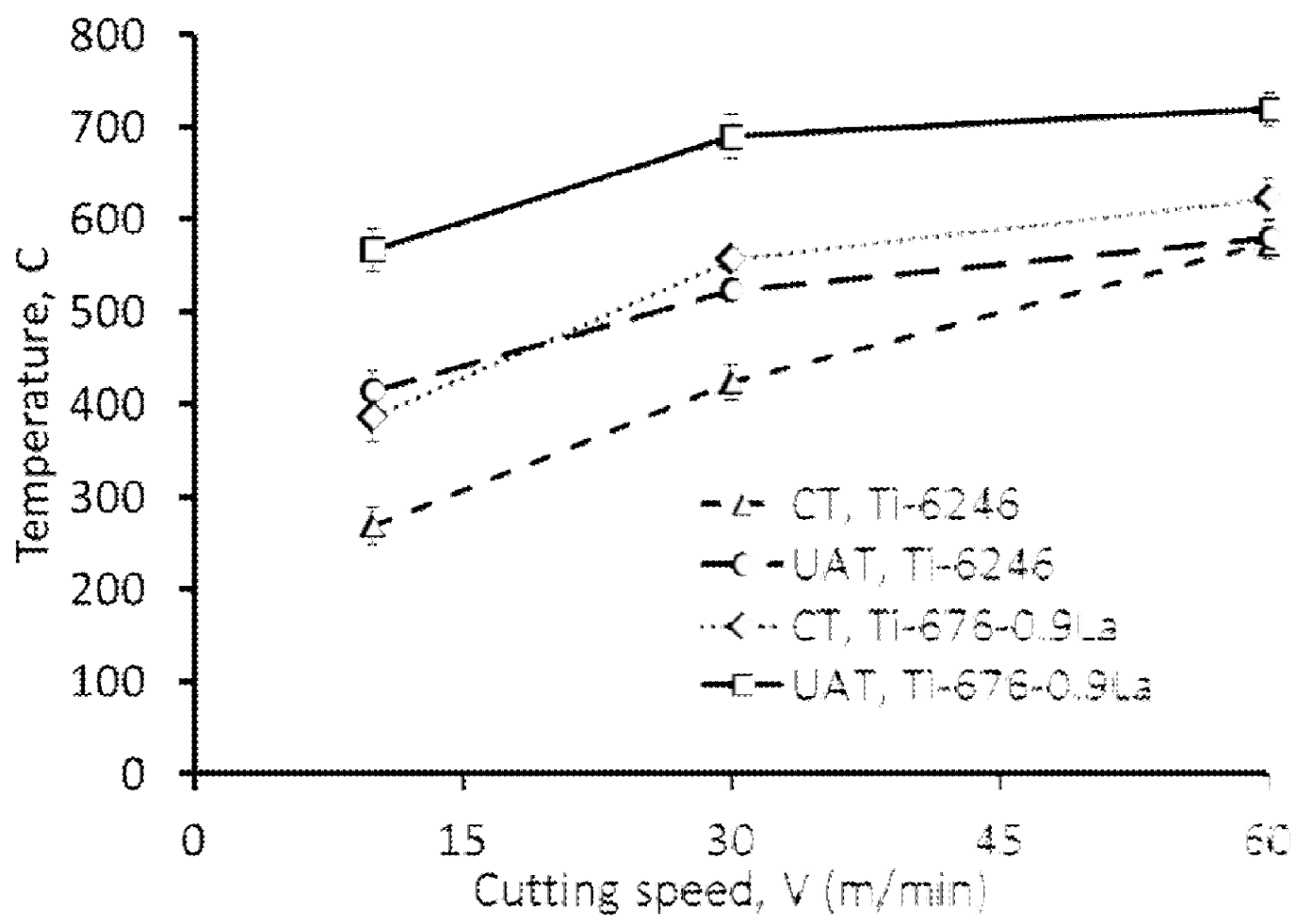

Figure 15: Temperature in process zone in CT and UAT for Ti-6246 and Ti-676-0.9La at $a_{p}=0.2$ $\mathrm{mm}$ for various cutting speeds.

\subsection{Surface Roughness}

Surface quality may be considered to be one of the vital factors in metal cutting as it is directly related to a fatigue life for most materials (Ulutan and Ozel, 2011). In this paper, surface roughness analyses were carried out for both alloys in CT and UAT to investigate the effect of the hybrid machining technique on a finished surface. The surface topology of a machined surface for both alloys in CT and UAT is shown in Figure 16. Amplitude parameters such as $R_{a}$ and $R_{q}$ showed improved surface quality for the modified alloys in both CT and UAT (Table 2) when compared to Ti-6246 (Leach, 2010). However, in UAT, significant reductions in excess of $50 \%$ were found in modified alloy. A considerable improvement in surface roughness in Ti-6246 
http://dx.doi.org/10.1016/j.jmatprotec.2013.12.002

was also observed in UAT when compared to CT. Similar observations are made with respect to the areal field parameters $\left(S_{a}, S_{q}\right)$ (Leach, 2010). Hence, UAT resulted in higher surface finish for both alloys. 


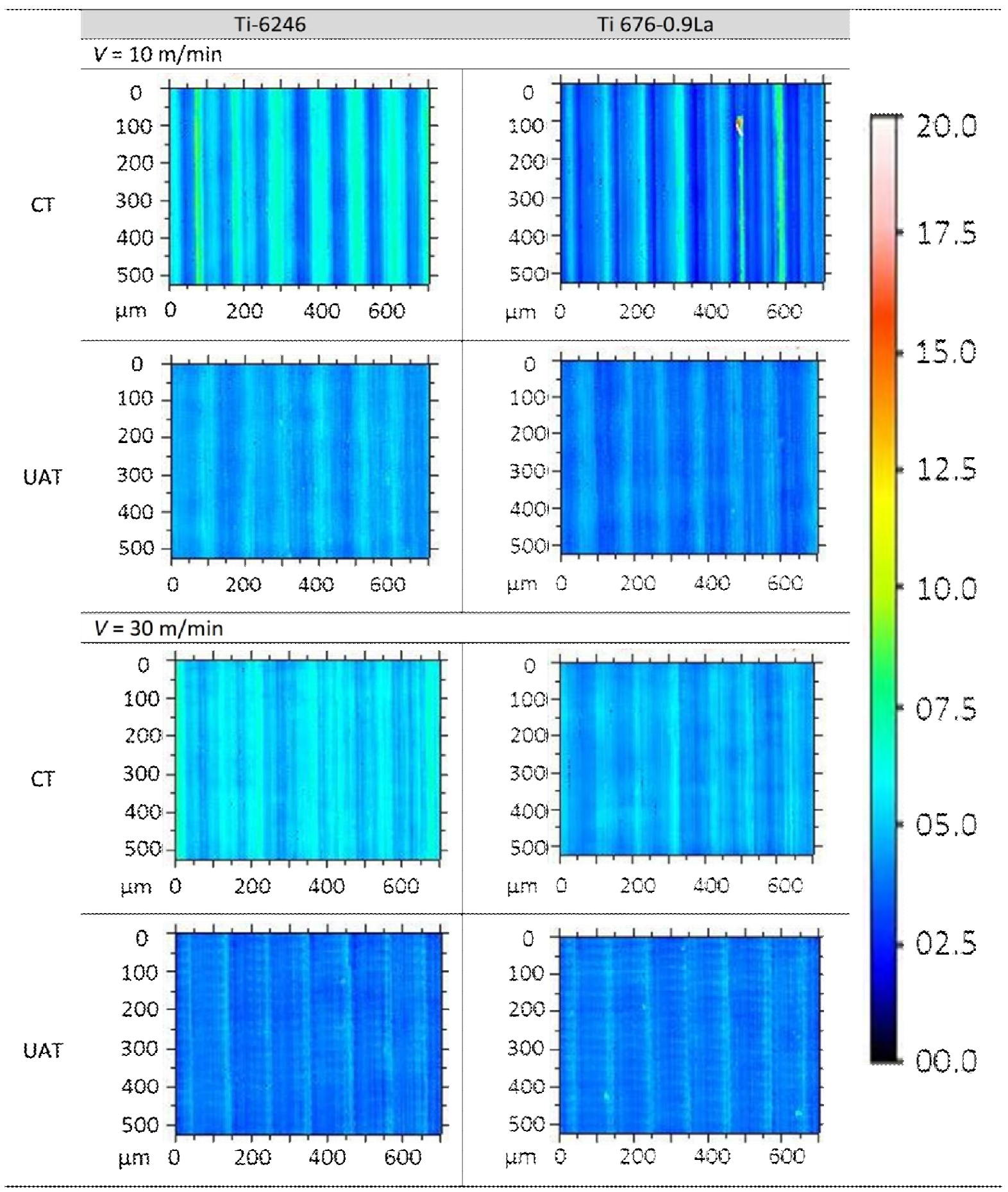

Figure 16: Surface profile scan for CT and UAT for both alloys at $a_{p}=0.2 \mathrm{~mm}$ for various cutting speeds. 
http://dx.doi.org/10.1016/j.jmatprotec.2013.12.002

Table 2. Parameter for surface roughness for CT and UAT for both alloys at $10 \mathrm{~m} / \mathrm{min}$ and $a_{p}=$ $0.2 \mathrm{~mm}$

\begin{tabular}{lcccc}
\hline & \multicolumn{2}{c}{ Ti-6246 } & \multicolumn{2}{c}{ Ti-676-0.9La } \\
\hline & CT & UAT & CT & UAT \\
\cline { 2 - 5 }$S_{q}$ & $1.05 \pm 0.36$ & $0.46 \pm 0.02$ & $0.91 \pm 0.26$ & $0.42 \pm 0.04$ \\
$S_{a}$ & $0.81 \pm 0.26$ & $0.38 \pm 0.02$ & $0.69 \pm 0.24$ & $0.33 \pm 0.03$ \\
$R_{a}$ & $0.82 \pm 0.20$ & $0.37 \pm 0.04$ & $0.72 \pm 0.20$ & $0.34 \pm 0.04$ \\
$R_{q}$ & $1.01 \pm 0.26$ & $0.45 \pm 0.05$ & $0.91 \pm 0.13$ & $0.38 \pm 0.05$ \\
\hline
\end{tabular}

\section{Conclusions}

The newly developed alloy Ti-676-0.9La responded well to UAT and CT at various cutting conditions. Addition of lanthanum resulted in precipitates as inter-grain impurity improved the chip formation process both in CT and UAT. Additionally, in UAT, the vibro-impact phenomena at the tool-workpiece-interface as well as the higher temperature in process zone improved the machinability with generation of shorter chips (as compared to CT). Furthermore, a significant reduction in cutting forces was observed in UAT for both alloys. Fine grains in the developed alloys improved its strength and resulted in good fatigue limit when compared to Ti-64 and Ti6246. Improved surface roughness was observed for both alloys machined with UAT. The newly developed alloy yields a better surface than the original alloy T-6246 in UAT.

\section{Acknowledgement}

Funding from the European Union Seventh Framework Programme (FP7/2007-2013) under grant agreement No. PITN-GA-2008-211536, project MaMiNa, is gratefully acknowledged.

The authors would also like to acknowledge Engineering and Physical Sciences Research Council (EPSRC), UK for providing FLIR SC3000 system for thermal analysis. 
http://dx.doi.org/10.1016/j.jmatprotec.2013.12.002

\section{References}

Ahmed, N., Mitrofanov, A.V., Babitsky, V.I., Silberschmidt, V.V., 2006. Stresses in ultrasonically assisted turning. Applied Mechanics and Materials 5, 351-358.

Arrazola, P.J., Garay, A., Iriarte, L.M., Armendia, M., Marya, S., Le Maître, F., 2009. Machinability of titanium alloys (Ti6AI4V and Ti555.3). Journal of Materials Processing Technology 209, 22232230.

Babitsky, V.I., Mitrofanov, A.V., Silberschmidt, V.V., 2004. Ultrasonically assisted turning of aviation materials: simulations and experimental study. Ultrasonics 42, 81-86.

Calamaz, M., Coupard, D., Girot, F., 2008. A new material model for 2D numerical simulation of serrated chip formation when machining titanium alloy Ti-6Al-4V. International Journal of Machine Tools and Manufacture 48, 275-288.

Donachie, M.J., 2004. Titanium- A technical guide, 2nd ed. ASM International, Ohio, USA.

Ezugwua, E.O., Da-Silvaa, R.B., Bonneya, J., Machadob, A.R., 2005. Evaluation of the performance of CBN tools when turning Ti-6Al-4V alloy with highpressurecoolant supplies. International Journal of Machine Tools and Manufacture 45, 1009-1014.

Hussain, M.S., Siemers, C., Rösler, J., 2013. Development of a Free-machining Titanium Alloy based on Ti 6AI 2Sn 4Zr 6Mo. Materials and Manufacturing Processes 28, 545-549.

Kitayama, S., Nagata, T., Nishimoto, M., Sugimoto, Y., W. Takahashi, W., 1992. Method for improving machinability of titanium and titanium alloys and free-cutting titanium alloys.

Komanduri, R., Brown, R.H., 1981. On the mechanics of chip segmentation in machining. Journal of Engineering for Industry 103, 33-51.

Komanduri, R., Hou, Z.B., 2002. On thermoplastic shear instability in the machining of a titanium alloy (Ti-6Al-4V), Metallurgical and Materials Transactions, 33(9), 2002, 2995-2301. Leach, R., 2010. Fundamental principles of engineering nano-metrology. Elsevier, Amsterdam. Maurotto, A., Muhammad, R., Roy, A., Babitsky, V.I., Silberschmidt, V.V., 2012. Comparing machinability of Ti-15-3-3-3 and Ni-625 alloys in UAT. Procedia CIRP 1, 330-335.

Maurotto, A., Muhammad, R., Roy, A., Silberschmidt, V.V., 2013. Enhanced ultrasonically assisted turning of a $\beta$-titanium alloy. Ultrasonics 53, 1242-1250. 
http://dx.doi.org/10.1016/j.jmatprotec.2013.12.002

Muhammad, R., Ahmed, N., Roy, A., Silberschmidt, V.V., 2012a. Turning of advanced alloys with vibrating cutting tool. Solid State Phenomena 188, 277-284.

Muhammad, R., Demiral, M., Roy, A., Silberschmidt, V.V., 2013a. Modelling the dynamic behaviour of hard-to-cut alloys under conditions of vibro-impact cutting. Journal of Physics: Conference Series 451, 1-11.

Muhammad, R., Maurotto, A., Roy, A., Silberschmidt, V.V., 2012b. Hot ultrasonically assisted turning of $\beta$-Ti alloy. Procedia CIRP 1, 336-341.

Muhammad, R., Maurotto, A., Roy, A., Silberschmidt, V.V., 2012c. Ultrasonically assisted turning of Ti-6Al-2Sn-4Zr-6Mo. Journal of Physics: Conference Series 382.

Muhammad, R., Roy, A., Silberschmidt, V.V., 2013b. Finite element modelling of conventional and hybrid oblique turning processes of titanium alloy. Procedia CIRP 8, 509-514.

Nategh, M.J., Razavi, H., Abdullah, A., 2012. Analytical modeling and experimental investigation of ultrasonic-vibration assisted oblique turning, part I: Kinematics analysis. International Journal of Mechanical Sciences 63, 1-11.

Peters, M., Leyens, C., 2002. Titanium and titanium alloys. Wiley-VCH Germany.

Rahman Rashid, R.A., Sun, S., Wang, G., Dargusch, M.S., 2012a. The effect of laser power on the machinability of the Ti-6Cr-5Mo-5V-4Al beta titanium alloy during laser assisted machining. International Journal of Machine Tools and Manufacture 63, 41-43.

Rahman Rashid, R.A., Sun, S., Wang, G., Dargusch, M.S., 2012b. An investigation of cutting forces and cutting temperatures during laser-assisted machining of the $\mathrm{Ti}-6 \mathrm{Cr}-5 \mathrm{Mo}-5 \mathrm{~V}-4 \mathrm{Al}$ beta titanium alloy. International Journal of Machine Tools and Manufacture 63, 58-69.

Rosler, J., Baker, M., Siemers, C., 2004. German Patent DE 10332078.

Shamoto, E., Moriwaki, T., 1994. Study on Elliptical Vibration Cutting. CIRP Annals Manufacturing Technology 43, 35-38

Shaw, M.C., Vyas, A., 1998. The mechanism of chip formation with hard turning steel. CIRP Annals - Manufacturing Technology 47, 77-82.

Shokrani, A., Dhokia, V., Newman, S.T., 2012. Environmentally conscious machining of difficultto-machine materials with regard to cutting fluids. International Journal of Machine Tools and Manufacture 57, 83-101. 
http://dx.doi.org/10.1016/j.jmatprotec.2013.12.002

Siemers, C., Bäker, M., Mukherji, D., Rösler, J., 2003. Microstructure evolution in shear bands during the chip formation of Ti6Al4V, Proceedings of Ti-2003 Wiley-VCH, Weinheim, Germany. Siemers, C., Brunke, F., Laukart, J., Hussain, M.S., Rösler, J., Saksl, K., Zahra, B., 2012. COM2012, Section Rare Earth Metals 2012, Niagara Falls, Canada, pp. 281-292.

Siemers, C., Brunke, F., Stache, M., Laukart, J., Zahra, B., Roesler, J., Rokicki, P., Saksl, K., $2011 a$. Advanced titanium alloys containing micrometer-size particles, 12th World Conference on Titanium (Ti-2011), Beijing, China, pp. 883-887.

Siemers, C., Jencus, P., Baeker, M., Roesler, J., Feyerabend, F., 2007. A new free machining Titanium alloy containing Lanthanum, Proceedings of the 11th World Conference on Titanium (Ti-2007), Kyoto, Japan, pp. 709-712.

Siemers, C., Laukart, J., Zahra, B., Rösler, J., Spotz, Z., K., S., 2011b. Development of advanced and free-machining alloys by micrometer-size particle precipitation. Materials Science Form 690, 262-265.

Siemers, C., Zahra, B., Leemet, T., Rösler, J., 2009. 8th AMMT’09 Conference,, St. Petersburg, Russia.

Sima, M., Özel, T., 2010. Modified material constitutive models for serrated chip formation simulations and experimental validation in machining of titanium alloy Ti-6Al-4V. International Journal of Machine Tools and Manufacture 50, 943-960.

Skelton, R.C., 1968. Turning with an oscillating tool. International Journal of Machine Tool Design and Research 8, 239-259.

Sutter, G., List, G., 2013. Very high speed cutting of Ti-6Al-4V titanium alloy - change in morphology and mechanism of chip formation. International Journal of Machine Tools and Manufacture 66, 37-43.

Ulutan, D., Ozel, T., 2011. Machining induced surface integrity in titanium and nickel alloys: A review. International Journal of Machine Tools and Manufacture 51, 250-280.

Weinert, K., Inasaki, I., Sutherland, J.W., Wakabayashi, T., 2004. Dry machining and minimum quantity lubrication. CIRP Annals - Manufacturing Technology 53, 511-537.

Zhang, X., Senthil Kumar, A., Rahman, M., Nath, C., Liu, K., 2012. An analytical force model for orthogonal elliptical vibration cutting technique. Journal of Manufacturing Processes 14. 
http://dx.doi.org/10.1016/j.jmatprotec.2013.12.002 